\title{
Gorillas in the crossfire: population dynamics of the Virunga mountain gorillas over the past three decades
}

\author{
José Kalpers, Elizabeth A. Williamson, Martha M. Robbins, Alastair McNeilage, Augustin Nzamurambaho, \\ Ndakasi Lola and Ghad Mugiri
}

\begin{abstract}
Small populations are particularly susceptible to disturbance. Routine censusing to monitor changes is important for understanding both population dynamics and the effectiveness of conservation strategies. Mountain gorillas Gorilla beringei beringei in the Virunga Volcanoes region of Rwanda, Uganda and the Democratic Republic of Congo have been censused five times since 1970 . However, due to war and political unrest in the region since 1990, no census had been conducted since 1989, when the population was thought to number 324 gorillas. In 2000 we estimated population size using repeated observations of 17 habituated groups and information on 15 unhabituated groups obtained during patrols. The minimum population was 359 gorillas, and a best-case scenario correcting for groups that might not have been counted was 395 . Using the minimum population and best-case scenario respectively, this represents a $0.9 \%$ or $1.8 \%$ annual growth rate over the last decade and $1.0 \%$
\end{abstract}

or $1.3 \%$ annual growth rate since 1972 . This is lower than growth estimates made in several population viability analyses, but approximately 5\% of the 1989 population is known to have died due to military activity over the last decade. Different subsets of the population exhibited different responses to disturbance caused by war. We discuss conservation strategies that are likely to have contributed to an increase in the gorilla population during this time of turmoil. While the population has grown, the results should be viewed with caution, not only because all known growth during the last decade can be attributed to one subset of the population, but also because the region is still plagued by political unrest.

Keywords Democratic Republic of Congo, Gorilla beringei beringei, war, population size, Rwanda, Uganda, Virunga Volcanoes.

\section{Introduction}

Small isolated populations of large, slow-reproducing species can be highly susceptible to disturbance. Responses to disturbance are variable and poorly understood, but

José Kalpers International Gorilla Conservation Programme, P.O. Box 48177 Nairobi, Kenya

Elizabeth A. Williamson Karisoke Research Centre, Dian Fossey Gorilla Fund International, 800 Cherokee Ave SE, Atlanta, GA 30315-1440, USA, and Department of Psychology, University of Stirling, Scotland.

Martha M. Robbins (Corresponding author) Max Planck Institute for Evolutionary Anthropology, Deutscher Platz 6, D-04103 Leipzig, Germany. E-mail: robbins@eva.mpg.de

Alastair McNeilage Institute for Tropical Forest Conservation, P.O. Box 44, Kabale, Uganda, and Wildlife Conservation Society, 185th Street and Southern Boulevard, Bronx, NY 10460, USA.

Augustin Nzamurambaho Parc National des Volcans, Office Rwandais du Tourisme et des Parcs Nationaux, B.P. 905, Kigali, Rwanda.

Ndakasi Lola Parc National des Virunga-sud, Institut Congolais pour la Conservation de la Nature, c/o IGCP-DRC, B.P. 137, Gisenyi, Rwanda.

Ghad Mugiri Mgahinga Gorilla National Park, Uganda Wildlife Authority, PO Box 3530, Kampala, Uganda.

Received 17 March 2002. Revision requested 29 August 2002. Accepted 20 November 2002. could have a critical impact on the ability of such populations to survive (Caughley, 1994; Harcourt, 1995). Monitoring is essential to understand responses and for assessing the effectiveness of management practices. We present a case study of changes in response to disturbance in a large, forest-dwelling mammal, which is also a highly visible flagship species: the mountain gorilla Gorilla beringei beringei of the Virunga Volcanoes in Central East Africa.

Mountain gorillas are categorized as Critically Endangered on the IUCN Red List (IUCN, 2002), and are found only in the Virunga Volcanoes region of Rwanda, Uganda and the Democratic Republic of Congo (DRC), and in Bwindi Impenetrable National Park in Uganda (although the subspecies classification of the Bwindi population is currently under debate; Groves, 2001; Stanford, 2001). Although the Virunga Volcanoes were given National Park status in 1925 to conserve the gorillas, they received little attention until the 1970s. The area surrounding the gorillas' habitat has one of the highest human population densities in Africa, at 400-600 people per $\mathrm{km}^{2}$ (Weber, 1995). Following the pioneering study by George Schaller (Schaller, 1963), long-term research and conservation efforts were initiated by Dian Fossey in the late 1960s, but the population continued to 
suffer from habitat degradation and poaching (Harcourt \& Fossey, 1981). Major new conservation programmes were underway by the end of the 1970s. These concentrated on three broad issues: the development of sustainable and economically viable gorilla-based tourism, support to the protected area authorities' anti-poaching programmes, and conservation education targeting resident populations around the Virunga Volcanoes. Under these programmes, the conservation status of the Virunga massif was greatly improved during the 1980s (Weber \& Vedder, 1983; Aveling \& Harcourt, 1984; Plumptre \& Williamson, 2001). However, the 1990s saw great fluxes of people travelling through or invading the forest. Fighting in the region began in January 1991 and continued intermittently until the genocide in Rwanda in 1994. Following liberation of the country by the Rwandan Patriotic Front, more than 800,000 Rwandan refugees entered DRC (then Zaïre), many of them by walking through the forest. Refugee camps established in Zaïre in 1994-1996 put tremendous pressure on the natural resources of the Virunga National Park (Henquin \& Blondel, 1997). These camps were emptied in October 1996 with the first liberation war in Zaïre. Since then the whole region has been severely affected by fighting and the movement of both rebel groups and regular armies. War and political unrest have had direct impacts on the gorilla population and its habitat, as well as increasing the likelihood of disease transmission from humans, with many people living in the forest under poor conditions of hygiene (Plumptre \& Williamson, 2001).

Over the past three decades, research projects have generated a wealth of information on the gorillas' demography, behavioural ecology and habitat (Robbins et al., 2001). Censuses of the Virunga gorillas were conducted at more or less 5-year intervals throughout the 1970s and 1980s and allowed changes in the population to be monitored. Due to political instability no census had been conducted since 1989, when there were estimated to be 324 gorillas (Sholley, 1991). Population modelling has shown that the Virunga gorilla population is viable for at least the next 100 years in the absence of external disturbance (Harcourt, 1995; Miller et al., 1998; Durant, 2000), but Harcourt (1995) stresses that the population could easily suffer a severe decline due to environmental perturbations such as habitat loss or degradation.

The aims of this paper are to assess the size of the population in 2000, evaluate growth rates, and compare our results with those from previous censuses. We also discuss the effects of war and propose factors and conservation actions that have contributed to the gorillas' survival during 10 years of civil unrest, together with implications for protected area management.

\section{Methods}

The Virunga Volcanoes Region encompasses three National Parks in three countries: Volcanoes National Park (Rwanda), Virunga National Park - Mikeno sector (Democratic Republic of Congo), and Mgahinga Gorilla National Park (Uganda) (Fig. 1). The Virunga Volcanoes contain a variety of afromontane habitats stratified by altitude: the Neoboutonia sp. zone, bamboo zone, HageniaHypericum zone, and sub-alpine and alpine zones (Schaller, 1963; McNeilage, 2001). Altitude ranges from 2,300 to $4,507 \mathrm{~m}$.

Schaller (1963) developed a technique to estimate gorilla group composition using nest counts and measurements of dung (dung diameter correlates with the size of an animal). All weaned gorillas build a new nest every evening. By following fresh trails to the most recent nests a total count of animals in each group can be obtained. During censuses in the 1970s and 1980s, three successive nest sites were counted for each group to account for any nests that might had been missed in a single count. To obtain accurate counts and avoid the possibility of a particular group being counted more than once (because gorillas move freely between Rwanda, DRC and Uganda), systematic searches through specific sectors of the Virunga Volcanoes were conducted with all three countries being surveyed simultaneously in a complete sweep across the gorilla habitat (Weber \& Vedder, 1983; Aveling \& Harcourt, 1984; Vedder \& Aveling, 1986; Sholley, 1991). Thus it was assumed that nest sites from nearly all gorilla groups would be located. A correction factor of $5 \%$ of the total gorillas counted was added to produce the 'estimated population size'. This was to account for missed infants (that leave no faeces to indicate their presence in their mothers' nests), for groups that might not have been counted, and in some cases was based on actual area missed (Table 2; Vedder \& Aveling, 1986; Sholley, 1991).

During the past decade the entire Virunga Volcanoes Region has not been accessible at any one time, and hence a comparable census has not been possible. A few areas in the centre of the massif were used intensively by armed groups and therefore were not patrolled during times of insecurity. Fig. 2a shows these areas, which we term the 'red zone' (area that has rarely been accessible to park staff), and the 'orange zone' (area that has been sporadically insecure). The orange zone represents c. $25 \%$ of the total area of the Virunga Volcanoes and the red zone $c .10 \%$. The few patrols that managed to enter the red zone over the last 3 years did however find evidence of gorillas on several occasions. An estimate of the size of the gorilla population in 2000 was based on a combination of individual identification of gorillas in habituated and regularly monitored groups, plus 


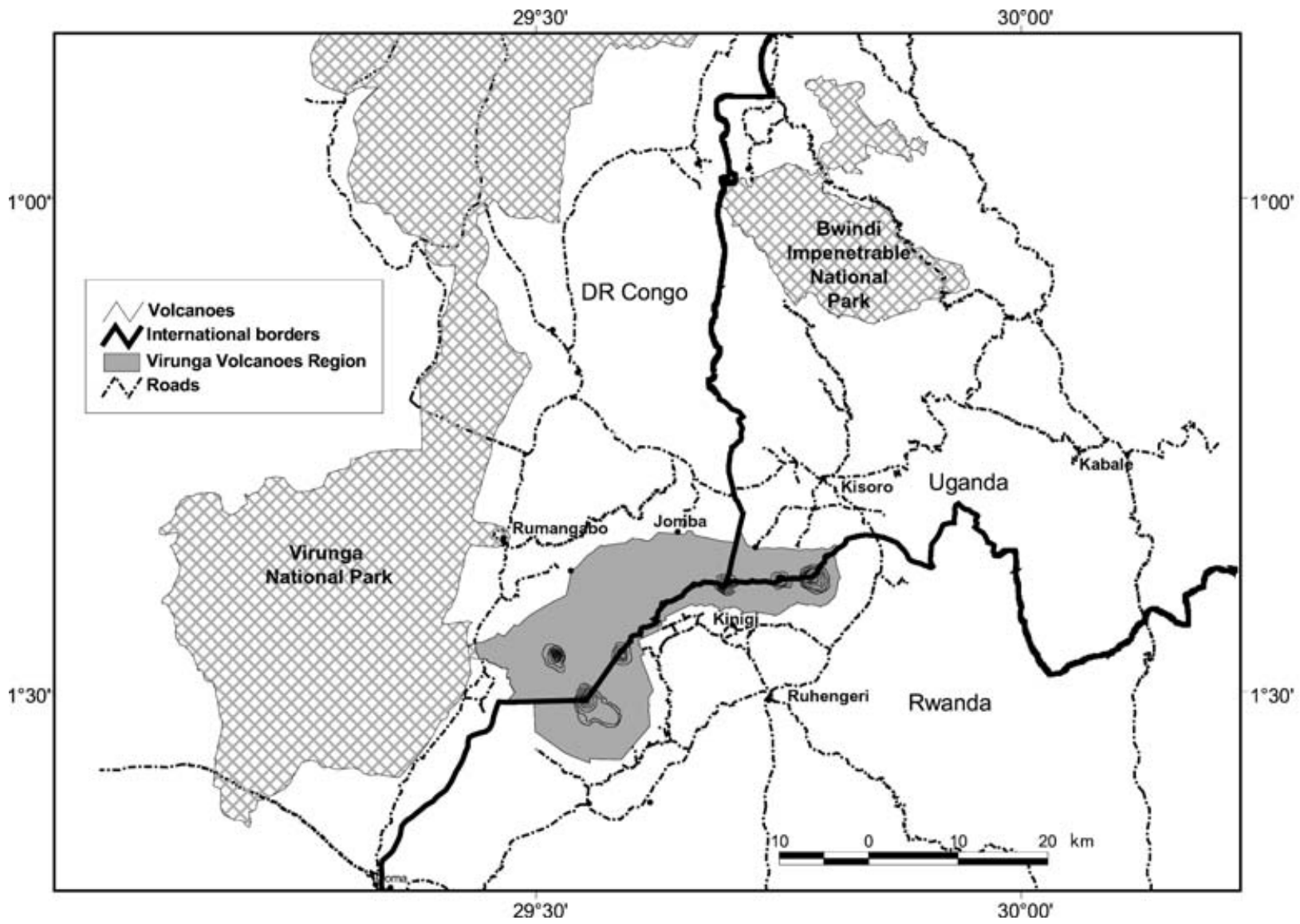

Fig. 1 The Virunga Volcanoes Region, straddling the borders of the Democratic Republic of Congo, Rwanda and Uganda.

opportunistically repeated nest counts of groups that are not monitored but were located by ranger patrols.

Park personnel and conservation organizations currently monitor 17 habituated groups for tourism or research. Each animal is known individually: it has been photographed, its 'noseprint' drawn, other physically distinctive characteristics noted, and demographic information systematically recorded. Thus precise numbers are known. We present information obtained through the daily monitoring of identified individuals in habituated groups; these groups were monitored on a daily basis, except when insecurity prevented access by rangers. Two conservation organizations have been studying habituated gorillas: 1) The International Gorilla Conservation Programme (a coalition of the African Wildlife Foundation, Fauna \& Flora International and the WWF), in collaboration with the three protected area authorities, launched a ranger-based monitoring programme throughout the Virunga Volcanoes in 1997; data collection began in DRC in October 1997, in Uganda in November 1998 and in Rwanda in July 1999 on a total of 14 habituated gorilla groups. 2) The Karisoke Research Centre, currently operated by the Dian Fossey Gorilla Fund International, has been studying several gorilla groups since 1967; detailed demographic information is available for three gorilla groups.

Two methods were used for counting unhabituated gorillas. Several groups and lone silverbacks live close to or have home ranges overlapping with the habituated groups. During regular daily patrols, rangers and gorilla trackers made repeated nest counts, and reliable estimates of the size and composition of these groups were obtained. For areas that were rarely accessed by patrols, such as the red zone, rangers recorded opportunistic observations of all unhabituated groups they came across, using the same technique of nest counting. To limit the possibility of double counting any unhabituated group, we took into account only groups that were either well known by the trackers and rangers, or that were observed once only and far $(c .5 \mathrm{~km})$ from each other during the same patrol.

We present analyses of 'worst-case' and 'best-case' scenarios. The worst-case scenario uses groups actually counted during this study. Our best-case scenario adds 
Table 1 Group compositions from the 2000 survey. Age and sex classifications are not known for unhabituated groups. Monitored groups ( $\mathrm{T}, \mathrm{R}$ and $\mathrm{H}$ ) correspond to those in Fig. 3 (names as given in 2000).

\begin{tabular}{|c|c|c|c|c|c|c|c|c|}
\hline $\begin{array}{l}\text { Group name or } \\
\text { Code }\end{array}$ & Group type* & Silverbacks & Blackbacks & $\begin{array}{l}\text { Adult } \\
\text { females }\end{array}$ & Sub-adults & Juveniles & Infants & Total \\
\hline Kabirizi & $\mathrm{T}$ & 1 & 0 & 11 & 2 & 0 & 11 & 25 \\
\hline Munyaga & $\mathrm{T}$ & 2 & 0 & 1 & 2 & 2 & 0 & 7 \\
\hline Humba & $\mathrm{T}$ & 1 & 0 & 4 & 0 & 0 & 4 & 9 \\
\hline Rugendo & $\mathrm{T}$ & 2 & 0 & 4 & 0 & 1 & 4 & 11 \\
\hline Kwitonda & $\mathrm{T}$ & 1 & 0 & 4 & 0 & 1 & 5 & 11 \\
\hline Mapuwa & $\mathrm{T}$ & 1 & 0 & 4 & 1 & 0 & 1 & 7 \\
\hline Lulengo & $\mathrm{T}$ & 1 & 2 & 0 & 2 & 0 & 0 & 5 \\
\hline Gr. $13^{\circ}$ & $\mathrm{T}$ & 1 & 1 & 3 & 0 & 0 & 2 & 7 \\
\hline Sabyinyo & $\mathrm{T}$ & 2 & 0 & 3 & 0 & 3 & 3 & 11 \\
\hline Amahoro & $\mathrm{T}$ & 2 & 1 & 8 & 1 & 2 & 6 & 20 \\
\hline Susa & $\mathrm{T}$ & 2 & 4 & 13 & 0 & 6 & 8 & 33 \\
\hline Nyakagezi & $\mathrm{T}$ & 2 & 0 & 3 & 0 & 2 & 3 & 10 \\
\hline Susa-sat1 & $\mathrm{H}$ & 0 & 3 & 0 & 0 & 0 & 0 & 3 \\
\hline Susa-sat2 & $\mathrm{H}$ & 1 & 0 & 1 & 0 & 1 & 0 & 3 \\
\hline Pablo & $\mathrm{R}$ & 3 & 2 & 17 & 6 & 6 & 13 & 47 \\
\hline Shinda & $\mathrm{R}$ & 6 & 3 & 7 & 0 & 3 & 3 & 22 \\
\hline Beetsme & $\mathrm{R}$ & 4 & 4 & 6 & 4 & 0 & 6 & 24 \\
\hline Mik 01 & $\mathrm{UH}$ & & & & & & & 8 \\
\hline Mik 02 & $\mathrm{UH}$ & & & & & & & 4 \\
\hline Mik 03 & $\mathrm{UH}$ & & & & & & & 11 \\
\hline Mik 04 & $\mathrm{UH}$ & & & & & & & 7 \\
\hline Mik 05 & $\mathrm{UH}$ & & & & & & & 9 \\
\hline Pnv 01 & $\mathrm{UH}$ & & & & & & & 8 \\
\hline Pnv 02 & UH & & & & & & & 10 \\
\hline Pnv 03 & $\mathrm{UH}$ & & & & & & & 5 \\
\hline Pnv 04 & $\mathrm{UH}$ & & & & & & & 4 \\
\hline Pnv 05 & $\mathrm{UH}$ & & & & & & & 7 \\
\hline Pnv 06 & $\mathrm{UH}$ & & & & & & & 6 \\
\hline Pnv 07 & $\mathrm{UH}$ & & & & & & & 4 \\
\hline Mgnp 01 & $\mathrm{UH}$ & & & & & & & 5 \\
\hline Mgnp 02 & $\mathrm{UH}$ & & & & & & & 3 \\
\hline Krc 01 & $\mathrm{UH}$ & & & & & & & 3 \\
\hline Solitary males & & & & & & & & 10 \\
\hline Habituated groups & & 32 & 20 & 89 & 18 & 27 & 69 & 255 \\
\hline Unhabituated groups & & & & & & & & 94 \\
\hline Total & & & & & & & & 359 \\
\hline
\end{tabular}

*T, tourist; H, habituated; R, research; UH, unhabituated.

Table 2 Population parameters for the Virunga mountain gorilla population from 1971 to 2000 (see text for explanation of estimated population size). For 2000, \% multi-male groups and \% immature are calculated from the 17 habituated groups only.

\begin{tabular}{|c|c|c|c|c|c|c|c|}
\hline $\begin{array}{l}\text { Census } \\
\text { years(s) }\end{array}$ & $\begin{array}{l}\text { Total gorillas } \\
\text { counted }\end{array}$ & $\begin{array}{l}\text { Estimated population } \\
\text { size }\end{array}$ & $\begin{array}{l}\text { No. of social } \\
\text { groups }\end{array}$ & $\begin{array}{l}\text { Mean group } \\
\text { size }\end{array}$ & $\begin{array}{l}\text { No. of solitary } \\
\text { males }\end{array}$ & $\begin{array}{l}\% \text { multi-male } \\
\text { groups }\end{array}$ & $\%$ immature \\
\hline $1971-73^{1}$ & 261 & 274 & 31 & 7.9 & 15 & 42.0 & 39.8 \\
\hline $1976-78^{2}$ & 252 & 268 & 28 & 8.8 & 6 & 39.0 & 35.8 \\
\hline $1981^{3}$ & 242 & 254 & 28 & 8.5 & 5 & 40.0 & 39.7 \\
\hline $1986^{4}$ & 279 & 293 & 29 & 9.2 & 11 & 8.0 & 48.2 \\
\hline $1989^{5}$ & 309 & 324 & 32 & 9.2 & 6 & 28.0 & 45.5 \\
\hline $2000^{6}$ & 359 & $359-395$ & 32 & 10.9 & 10 & 52.9 & 44.7 \\
\hline
\end{tabular}

${ }^{1}$ Harcourt \& Groom (1972), Groom (1973).

${ }^{2}$ Weber \& Vedder (1983).

${ }^{3}$ Aveling \& Harcourt (1981).

${ }^{4}$ Vedder \& Aveling (1986).

${ }^{5}$ Sholley (1991).

${ }^{6}$ This study. 

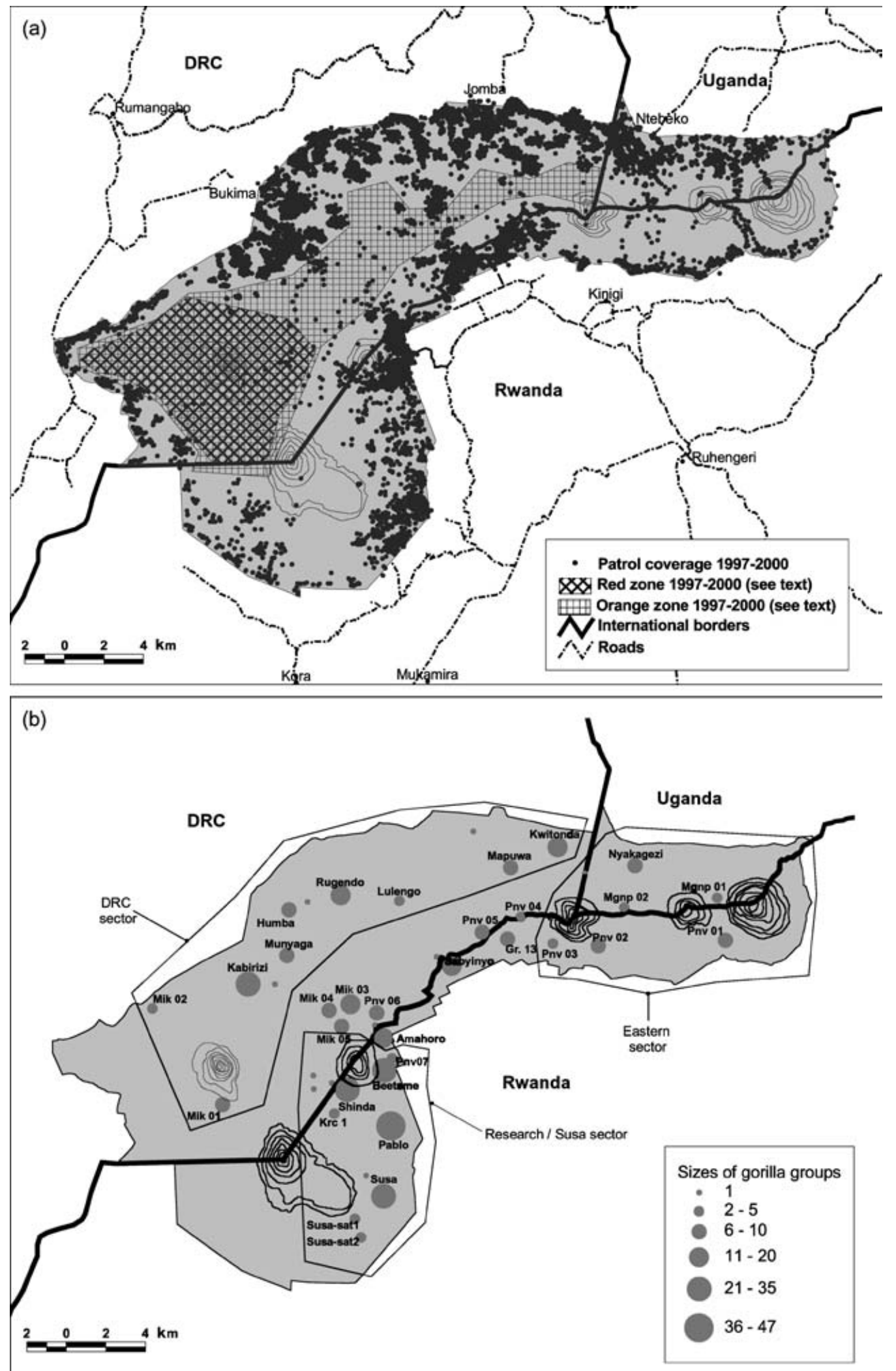

Fig. 2 The Virunga Volcanoes Region, illustrating (a) the 'red zone' and 'orange zone' of patrol coverage for 1997-2000 (see text for further details), and (b) the 2000 Virunga population survey, with locations and sizes of gorilla groups, and population sectors (see text for further details). Group names correspond to those in Table 1. 
$10 \%$ to the overall count. This correction was based on several factors and is a conservative estimate. We justify using a $10 \%$ correction factor instead of the $5 \%$ used in previous censuses because the red zone that was rarely patrolled represents c. $10 \%$ of the Virunga Volcanoes Region. During the 1989 census, c. $11 \%$ of the total population counted was located in the area we call the red zone.

The proportion of the gorilla population that is immature ( $<8$ years of age) has been used as a measure of the 'health' of the population (c.f. Weber \& Vedder, 1983; Sholley, 1991). Other age classes we used are: infants (0-3.5 years), juveniles (3.5-6 years), subadults (6-8 years), adult females ( $8+$ years), blackbacks (8-12 years), and silverbacks (12+ years) (c.f. Weber \& Vedder, 1983; Sholley, 1991). Growth rates were calculated using the formula:

$\%$ increase per annum $=\left(\left(P_{\mathrm{x}} / P_{\mathrm{o}}\right)^{1 / \mathrm{x}} * 100\right)-100$,

where $\mathrm{x}=$ number of years, $P_{\mathrm{o}}=$ population size at year 0 , and $P_{\mathrm{x}}$ is population at year $\mathrm{x}$.

As with previous censuses, different sectors of the Virunga Volcanoes were compared, focusing on basic demographic factors such as gorilla numbers, growth rates and percentage of immature individuals (Weber \& Vedder, 1983; Steklis \& Gerald-Steklis, 2001).

\section{Results}

\section{Population size and structure in 2000}

A minimum of 359 gorillas inhabited the Virunga Volcanoes at the end of 2000 (Table 1; Fig. 2b). The 17 groups habituated for research or tourism contained 255 individuals, and 15 unhabituated groups contained a minimum of 94 individuals. In addition, 10 solitary males were identified in the population. Therefore, the worstcase scenario is an actual count of 359 gorillas. Our estimate of the best-case scenario, using a $10 \%$ correction factor, is 395 gorillas.

Median and mean group size were 8 and 11 individuals respectively. Habituated groups (mean $=15$, range 3-47) were significantly larger than the unhabituated groups (mean $=6.3$, range 3-11; Mann-Whitney $U$ test, $n_{1}=17$, $\left.n_{2}=15, U=194.5, \mathrm{P}=0.011\right)$. There will have been a slight underestimate of unhabituated gorillas due to young infants being missed from nest counts but this does not explain the whole difference. Increased protection may lead to larger groups as a result of daily monitoring, although habituated groups were not randomly chosen for habituation and might have been larger from the outset. The percentage of immature individuals in the population was $45 \%$ (habituated groups only). Nine of $17(53 \%)$ habituated groups contained more than one silverback (range 1-6).

\section{Effects of war during the past decade}

Between 1992 and 2000, 12-17 gorillas died as a direct result of military activity (Fig. 3). These individuals represent $4-5 \%$ of the 1989 population. It is possible that more gorillas died, especially in unhabituated groups, but probably not on a large scale because such information would spread rapidly by word of mouth, as park rangers and some local people generally assist the military authorities on all sides of the borders. Aside from the loss of individuals, given the social structure of gorillas, there are detrimental effects on surviving individuals in the social units when the dominant silverback dies. In the absence of a competent silverback, females usually emigrate into other groups and outsider silverbacks will kill infants under the age of three to induce females to resume ovulating more rapidly than if their infants survived (Watts, 1989; Robbins, 1995). Entire groups may disintegrate. Therefore while the killing of four silverbacks might appear less detrimental than the killing of four reproductively active females, the impacts can be devastating.

\section{Changes in gorilla numbers in subsets of the Virunga population}

Previous census reports have divided the Virunga Volcanoes into sectors to assess population dynamics and the effectiveness of conservation strategies in different regions (Weber \& Vedder, 1983; Aveling \& Harcourt, 1984; Steklis \& Gerald-Steklis, 2001). While the methods used in this survey are not directly comparable to previous censuses, we can still examine the dynamics of three subsets of the population (Fig. 2b) that have differed greatly over the past decade.

The eastern section of the Virunga Volcanoes (including Mount Sabyinyo and areas to the east) has long been an area of concern to conservationists because of its small size, long border, and isolation from the main body of the Parks (Groom, 1973; Harcourt \& Fossey, 1981; Weber \& Vedder, 1983). In the 1970s there were only 34-36 gorillas in this region, but the number increased to $c .57$ in 1989. In the early 1990s this area was subject to intense military activity but our results indicate that there are at least 57 gorillas still remaining in this region. While this is encouraging, the major problem with considering the eastern section as a separate entity and making comparisons across censuses is that the boundary used to 


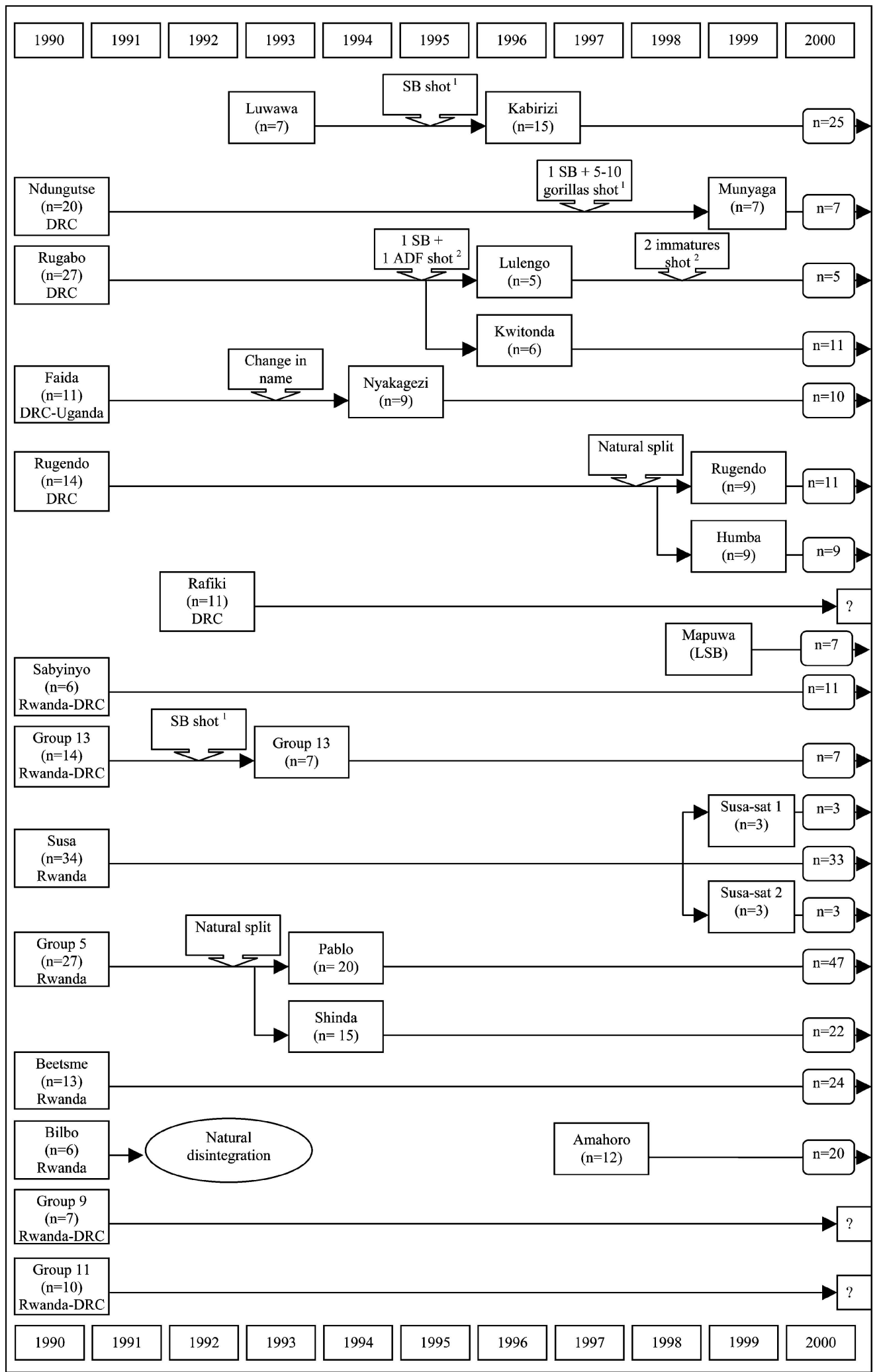

Fig. 3 Time line of changes among the habituated gorilla groups in the Virungas over 1990-2000. Names are group names, usually named after the dominant silverback. Names of some groups were changed between 1990 and 2000 because of a change of the dominant silverback (to cross-reference to Table 1, use the group name in 2000). SB, silverback; LSB, lone silverback; ADF, adult female; n, group size; ?, fate of group unknown (lack of access due to insecurity); 1, accidental; 2, deliberate. 
Fig. 4 Changes in the Virunga gorilla population from 1971 to 2000 , illustrating the worst-case scenario, best-case scenario and projected growth (see text for further details).

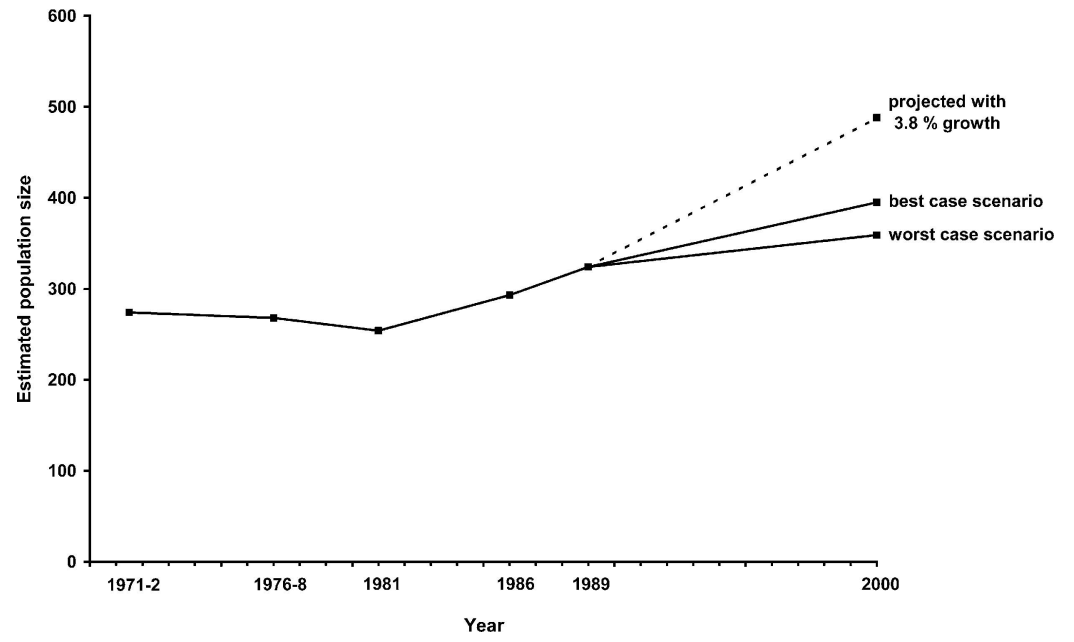

differentiate it is somewhat arbitrary and inconsistent, and several groups may move in and out of the area.

Another subset to consider is the groups habituated for tourism in the Democratic Republic of Congo. In 1996 there were seven habituated groups in this area totalling 92 gorillas (Sikubwabo \& Mushenzi, 1997). In 2000 there were still seven habituated groups but they totalled only 75 gorillas (Fig. 3). This represents a decline of nearly $20 \%$ in only 4 years. This may in part be due to natural emigration of individuals out of habituated into unhabituated groups, but it is known that the decline in several groups was due to the killing of silverbacks and consequent emigration of group members into other groups (see Fig. 3 and above).

The sector for which we have the most detailed information on demographic change consists of the three groups monitored by the Karisoke Research Centre and one of the tourism groups, the Susa group, which ranges south of the research groups (hereafter referred to as the research plus Susa sector). In 1989 these four groups contained 80 individuals. In the past decade, no individuals have immigrated to these groups from outside the area but females have transferred amongst the four groups. The major demographic changes have been the disintegration of the all-male group (Bilbo group) when the five males became lone individuals, the splitting of Group 5 to form two groups, and the formation of two groups of three individuals each that are satellites to the Susa Group (Fig. 3). In 2000 the total number in these groups was 132 . Therefore, excluding five emigrant males, there was a $76 \%$ increase in the size of this population subset, with a $5.3 \%$ annual growth rate. The increased number of gorillas in this subset accounts for more than the known overall increase in population size with the worst-case scenario of 359 gorillas.

\section{Population changes over the past three decades}

Using the minimum population count of 359 individuals, there has been a $10 \%$ increase in population size over the past decade, equivalent to a $0.9 \%$ annual growth rate (Fig. 4). Whilst this is notably higher than the negative growth rate of $-0.8 \%$ experienced in the $1970 \mathrm{~s}$ (1972-1981 censuses), it is much lower than the $3.1 \%$ annual growth exhibited between the 1981 and 1989 censuses (Table 2). From 1972 to 2000, the population has experienced an overall annual growth rate of $1.0 \%$.

Using the best-case scenario estimate of 395 individuals, the population has increased by $18 \%$ since 1989 and experienced a $1.8 \%$ annual growth rate (Fig. 4). Even this is considerably lower than both the annual growth rate of $3.1 \%$ observed in the $1980 \mathrm{~s}$ and the projected annual growth rate of $3.8 \%$ predicted by a population and habitat viability analysis (Fig. 4; Miller et al., 1998). Between 1972 and 2000 the growth rate with our best-case scenario was $1.3 \%$ per year.

In addition to comparing the actual size of the population and growth rates, we can consider changes in various population parameters (Table 2). There has been a slow but steady increase in the number of groups and mean group size over time. The increase in group size between 1989 (mean $=9.2$, range 2-34) and 2000 (mean $=10.9$, range 2-47) was not significant (MannWhitney $U$ test, $n_{1}=32, n_{2}=32, U=496.5, \mathrm{P}=0.835$ ). The immature proportion of the population remained over $40 \%$ for the past 15 years, indicating a healthy population that theoretically should continue to grow in the absence of abnormally high mortality rates (Harcourt et al., 1981; Dobson \& Lyle, 1989; Harcourt, 1995). The population has fluctuated in the percentage of groups that are multi-male (Table 2), probably as a result of 
natural variation in sex ratio and dispersal patterns over time (Robbins, 1995) as well as the effects of poaching that specifically targeted silverbacks (Weber \& Vedder, 1983). The calculation of $53 \%$ multi-male groups based solely on the habituated groups for the 2000 results is probably high because these groups are significantly larger than the unhabituated ones and larger groups usually contain more silverbacks (Robbins, 1995).

\section{Discussion}

Despite 10 years of war and civil unrest, the mountain gorilla population in the Virunga Volcanoes increased to a minimum of 359 individuals by the year 2000 . However, the impact of this disturbance has varied across the population and some sectors suffered considerably more than others. In light of these findings, we are able to discuss the changes in mountain gorilla population dynamics over the past 30 years, the effects of civil unrest and armed conflict on gorilla conservation, and effective strategies for protected area management.

The population was stable or in a slow decline during the 1970s. This was followed by an average growth rate of $3 \%$ per year in the 1980s, and then a slower increase of $c .1 \%$ per year in the 1990s. These changes in growth rate reflect variation in human disturbance and conservation activities during the different decades. The 1970s were marked by direct poaching of gorillas and cattle grazing in the park. The 1980s saw an increase in conservation activities such as education and patrolling and the 1990s saw war and political instability with direct killings of gorillas, habitat degradation and the interruption of conservation activities, most notably patrols (Harcourt \& Groom, 1972; Groom, 1973; Weber \& Vedder, 1983; Aveling \& Harcourt, 1984; Kalpers, 2001; Plumptre \& Williamson, 2001; Steklis \& GeraldSteklis, 2001). It is astounding that there has been no major population decrease in the last decade despite the severity of human disturbance in the Virunga Volcanoes.

However our results also reveal that the overall increase in the Virunga population can be accounted for by the research plus Susa sector alone. The contrasts between the various subsets of the Virunga population are likely to be a result of differing levels of human disturbance, ecological conditions and demographic factors. The tourism groups in the Democratic Republic of Congo have experienced a high, human-induced mortality rate, as for many years these gorillas ranged in areas intensively used by various armed groups. In comparison, the research plus Susa sector has received better protection during the past three decades and, in the 1990s in particular, was subject to heavy disturbance for a shorter period of time (1997-98). Additionally, the area utilized by the research plus Susa sector is believed to provide some of the best habitat for gorillas in terms of food availability (McNeilage, 2001). These four groups have been predominantly multi-male, and as such there might have been reduced risk of infanticide, leading to improved survivorship and group stability (Robbins, 1995, 2001; Watts, 2000; Steklis \& Gerald-Steklis, 2001).

The variability in population growth between the different sectors also demonstrates the value of longterm, population-wide data when assessing the viability of a small population. Previous population models of the Virunga gorillas used demographic data from monitored groups only (Harcourt, 1995; Miller et al., 1998; Durant, 2000), which exhibited higher growth rates than groups that were not monitored. If the whole population had experienced the 3.8\% growth rate used in Miller et al. (1998), the population should have grown to 488 individuals by 2000 (Fig. 4). Therefore caution should be exercised when using demographic information obtained from one subset to extrapolate to an entire population.

One of the principal conservation activities in the Virunga Volcanoes has been regular tracking and monitoring of gorillas habituated for research or tourism. Approximately 260 gorillas are followed and observed on a daily basis (security permitting); this routine activity has both costs and benefits. Threats associated with the habituation of wild gorillas include higher exposure to human-borne diseases, an increase in the ease of approaching and subsequently harming the gorillas, and overall disturbance of behaviour patterns (Butynski \& Kalina, 1998; Woodford et al., 2002). However, daily monitoring allows proactive 'close-protection' of those gorillas, such as checking on the physical condition of individuals, removal of snares set in their habitat, and veterinary intervention in emergency situations. The groups that have been most closely monitored (the research plus Susa sector) have experienced the highest growth rates during the last decade.

In contrast to the Virunga gorilla population, other populations of gorillas have been seriously affected by armed conflicts, such as eastern lowland gorillas Gorilla beringei graueri in Kahuzi-Biega National Park, DRC. The number of gorillas in the high-altitude zone of KahuziBiega was reduced by almost $50 \%$ in only 4 years, from 245 individuals in 1996 to only 130 in 2000 (WCS, 2000). In this case the drastic increase in direct gorilla hunting was exacerbated by the hostility of the local communities towards the park (Yamagiwa, 2001), and the lack of any taboo in the area against eating primates.

The relatively encouraging situation in the Virunga Volcanoes may be explained by the combination of four positive factors. Firstly, in contrast to the area surrounding Kahuzi-Biega National Park, for cultural reasons 
the resident communities in the Virunga region do not eat gorillas, even though there has been an increase in trapping of some large mammals such as antelopes (Plumptre et al., 1997). Most gorilla casualties in the Virunga Volcanoes have been caused accidentally rather than deliberately. Secondly, the size of the entire Virunga massif is only $7 \%$ of that of Kahuzi-Biega, which makes it easier to access and control. Thirdly, the Virunga gorillas are still recognized as an important economic resource (through tourism) by the national and local authorities of the three countries sharing this forest block. During the various phases of the conflict, many of the warring factions have actually shown commitment and invested resources to ensure that the gorillas were not harmed (pers. obs.). Fourthly, conservation strategies developed over the past three decades probably had a durable impact on local people's attitudes and on the commitment of Park staff. Extensive education programmes were operational prior to the war, and some projects continued their outreach activities during the conflict years. In addition, several international conservation organizations continued their support to the Parks' authorities throughout the war, assisting their surveillance and management efforts by supplying equipment, paying staff salaries and capacity building. Long-term support prevented these authorities from undergoing major institutional collapse.

In addition to the conservation strategies shown to be effective during times of peace in the Virunga Volcanoes, our experiences over the last 10 years of mountain gorilla conservation allow lessons to be learnt that may be applicable in similar conflict situations (see also Fimbel \& Fimbel, 1997; Hart \& Hart, 1997). From a management perspective the factors underlying the relatively encouraging state of the gorilla population indicate that: 1) Continual financial and moral support to the protected area authorities is essential during times of civil unrest; in particular, dedicated local field personnel, especially junior staff, are critical to ensuring that surveillance and monitoring activities continue. 2) Conservation strategies during times of peace should focus on capacity building and institutional strengthening to improve the ability of institutions to respond to and cope with crisis situations. 3) Military personnel at all levels should be the target of ongoing conservation education programmes during armed conflict. 4) Rehabilitation of institutions should be undertaken as soon as security permits staff to operate on the ground; conservation organizations should not wait for the complete return of stability, as situations are rarely predictable and periods of relative calm can be critical opportunities for intervention. 5) A system of trans-boundary protected areas such as the Virunga Volcanoes can provide potentially useful buffers to vulnerable populations; not only can animals move from one location to another as areas of human activity shift, but also conservation programmes can at least maintain their activities in more stable, neighbouring sections of the trans-boundary complex.

In conclusion, this study has shown that under particular circumstances a small population of a large, slow-reproducing, Critically Endangered mammal can survive the impact of severe disturbance and increase in size. Conservation can be achieved under difficult conditions such as prolonged armed conflict. However, despite these results giving us reason for cautious optimism, there is no room for complacency. In particular, a recurrence of direct poaching of mountain gorillas was observed in 2002, resulting in the deaths of at least 7 individuals. A population can always decrease rapidly, and population growth will always be limited by demographic factors specific to the species. Close monitoring of such a small population and continued support to conservation efforts will always be critical for the survival of the mountain gorillas of the Virunga Volcanoes.

\section{Acknowledgements}

We have greatly benefitted from the comments and suggestions of Maryke Gray, Annette Lanjouw, Andrew Plumptre, Jean-Claude Ruwet, Dieter Steklis and two anonymous reviewers. We are grateful to the protected area authorities of the three countries, the Institut Congolais pour la Conservation de la Nature, the Office Rwandais du Tourisme et des Parcs Nationaux, and Uganda Wildlife Authority for their cooperation. We acknowledge support from the International Gorilla Conservation Programme, the Dian Fossey Gorilla Fund International, the Max Planck Society, the Institute for Tropical Forest Conservation and the Wildlife Conservation Society. This study is the result of many years of observation in the Virunga Region, and as such, has been based on the daily work of field staff in the three countries. It is impossible to name them all here, but we would like to pay a special tribute to all the rangers, gorilla guides, trackers and wardens who have shown such immense dedication in conserving the natural resources of the Democratic Republic of Congo, Rwanda and Uganda. During the past 10 years of armed conflict, many have died or lost family members, and these courageous men and women deserve the recognition of the conservation community. Their sacrifices have not been in vain: thanks to them, the Afro-montane ecosystem has been preserved, and the mountain gorilla, both a biological and an economic resource, still survives in 2003. 


\section{References}

Aveling, C. \& Harcourt, A.H. (1984) A census of the Virunga gorillas. Oryx , 18, 8-13.

Butynski, T. \& Kalina, J. (1998) Gorilla tourism: a critical look. In Conservation of Biological Resources (eds E.J. MilnerGulland \& R. Mace), pp. 294-388. Blackwell Science, Oxford, UK.

Caughley, G. (1994) Directions in conservation biology. Journal of Animal Ecology, 63, 215-244.

Dobson, A.P. \& Lyles, A.M. (1989) The population dynamics and conservation of primate populations. Conservation Biology, 3, 362-380.

Durant, S. (2000) Dispersal patterns, social structure and population viability. In Behaviour and Conservation (eds M. Gosling \& B. Sutherland), pp. 172-197. Cambridge University Press, Cambridge, UK.

Fimbel, C. \& Fimbel, R. (1997) Conservation and civil strife: two perspectives from Central Africa: Rwanda: the role of local participation. Conservation Biology, 11, 309-310.

Groom, A.F.G. (1973) Squeezing out the mountain gorillas. Oryx, 2, 207-215.

Groves, C. (2001) Primate Taxonomy. Smithsonian Institute Press, Washington, DC, USA.

Harcourt, A.H. (1995) Population viability estimates: theory and practice for a wild gorilla population. Conservation Biology, 9, 134-142.

Harcourt, A.H. \& Groom, A.F. (1972) Gorilla census. Oryx, 11, 355-363.

Harcourt, A.H. \& Fossey, D. (1981) The Virunga gorillas: decline of an 'island' population. African Journal of Ecology, 19, 83-97.

Harcourt, A.H., Fossey, D. \& Sabater Pi, J. (1981) Demography of Gorilla gorilla. Journal of Zoology, 195, 215-233.

Hart, T. \& Hart, J. (1997) Conservation and civil strife: two perspectives from Central Africa: Zaire: New Models for an emerging state. Conservation Biology, 11, 308-309.

Henquin, B. \& Blondel, N. (1997) Etude par télédétection sur l'évolution récente de la couverture boisée du Parc National des Virunga, deuxième partie (période 1995-1996). ADG, Gembloux, Belgium.

IUCN (2002) 2002 IUCN Red List of Threatened Species. IUCN, Gland, Switzerland [http:/ / www.redlist.org, accessed 17 April 2003].

Kalpers, J. (2001) Volcanoes under Siege: Impact of a Decade of Armed Conflict in the Virungas. Biodiversity Support Program, Washington, DC, USA.

McNeilage, A. (2001) Diet and habitat use of two mountain gorilla groups in contrasting habitats in the Virungas. In Mountain Gorilla: Three Decades of Research at Karisoke (eds M.M. Robbins, P. Sicotte \& K.J. Stewart), pp. 265-292. Cambridge University Press, Cambridge, UK.

Miller, P., Babaasa, D., Gerald-Steklis, N., Robbins, M.M., Ryder, O.A. \& Steklis, D. (1998) Population biology and simulation modeling working group report. In Can the Mountain Gorilla Survive? Population and Habitat Viability Assessment for Gorilla gorilla beringei (eds S. Werikhe, L. Macfie, N. Rosen \& P. Miller), pp. 71-105. IUCN/SSC Conservation Breeding Specialist Group, Apple Valley, USA.
Plumptre, A.J., Bizumuremyi, J.B., Uwimana, F. \& Ndaruhebeye, J.D. (1997) The effects of the Rwandan civil war on poaching of ungulates in the Parc National des Volcans. Oryx, 31, 265-273.

Plumptre, A.J. \& Williamson, E.A. (2001) Conservation-oriented research in the Virunga region. In Mountain Gorilla: Three Decades of Research at Karisoke (eds M.M. Robbins, P. Sicotte \& K.J. Stewart), pp. 361-389. Cambridge University Press, Cambridge, UK.

Robbins, M.M. (1995) A demographic analysis of male life history and social structure of mountain gorillas. Behaviour, $132,21-47$.

Robbins, M.M. (2001) Variation in the social system of mountain gorillas: the male perspective. In Mountain Gorilla: Three Decades of Research at Karisoke (eds M.M. Robbins, P. Sicotte \& K.J. Stewart), pp. 29-58. Cambridge University Press, Cambridge, UK.

Robbins, M.M., Sicotte, P. \& Stewart, K.J. (eds) (2001) Mountain Gorilla: Three Decades of Research at Karisoke. Cambridge University Press, Cambridge, UK.

Schaller, G.B. (1963) The Mountain Gorilla: Ecology and Behaviour. University of Chicago Press, Chicago, USA.

Sholley, C. (1991) Conserving gorillas in the midst of guerrillas. In American Association of Zoological Parks and Aquariums, Annual Conference Proceedings (ed. Wheeling), pp. 30-37. West Virginia, USA.

Sikubwabo, C. \& Mushenzi, N. (1997). Mountain gorillas of Mikeno, Zaïre: an explosive situation. Gorilla Conservation News, 11, 2-3.

Stanford, C.B. (2001) The subspecies concept in primatology: the case of mountain gorillas. Primates, $\mathbf{4 2 ,}$ 309-318.

Steklis, D. \& Gerald-Steklis, N. (2001) Status of the Virunga mountain gorilla population. In Mountain Gorilla: Three Decades of Research at Karisoke (eds M.M. Robbins, P. Sicotte \& K.J. Stewart), pp. 391-412. Cambridge University Press, Cambridge, UK.

Vedder, A. \& Aveling, C. (1986) Census of the Virunga Population of Gorilla gorilla beringei. Unpublished Coordinator's Report, September 1986, Wildlife Conservation Society, New York, USA.

Watts, D.P. (1989) Infanticide in mountain gorillas: new cases and a reconsideration of the evidence. Ethology, 81, 1-18.

Watts, D.P. (2000) Causes and consequences of variation in male mountain gorilla life histories and group membership. In Primate Males (ed. P. Kappeler), pp. 169-179. Cambridge University Press, Cambridge, UK.

WCS (Wildlife Conservation Society) (2000) In Congo, Endangered Gorilla Population Cut in Half by Rebels. Wildlife Conservation Society Press Release, New York, USA [http://wcs.org/news/wcsreports/6989].

Weber, W. (1995) Monitoring awareness and attitude in conservation education: the mountain gorilla project in Rwanda. In Conserving Wildlife: International Education and Communication Approaches (ed. S.K. Jacobson), pp.28-48. Columbia University Press, New York, USA.

Weber, A.W. \& Vedder, A. (1983) Population Dynamics of the Virunga Gorillas: 1959-1978. Biological Conservation, 26, 341-366.

Woodford, M.H., Butynksi, T.M. \& Karesh, W.B. (2002) Habituating the great apes: the disease risks. Oryx, 36, 153-160. 
Yamagiwa, J. \& Kahekwa, J. (2001) Dispersal patterns, group structure, and reproductive parameters of eastern lowland gorillas at Kahuzi in the absence of infanticide. In Mountain Gorilla: Three Decades of Research at Karisoke (eds M.M. Robbins, P. Sicotte \& K.J. Stewart), pp. 89-122. Cambridge University Press, Cambridge, UK.

\section{Biographical sketches}

Mountain gorilla conservation in the Virungas has depended on the cooperation of the three protected areas, as well as on the conservation and research organizations supporting their work. The authors have worked across all aspects of this work. Augustin Nzamurambaho, Ndakasi Lola and Ghad Mugiri supervise ranger-based monitoring and related programmes for the three National Parks. José Kalpers worked for over 10 years with the International Gorilla Conservation Programme, developing the monitoring programmes and other initiatives supporting park management. Liz Williamson has studied the feeding ecology of western lowland gorillas, participated in population surveys of gorillas, and served as director of the Karisoke Research Centre. Martha Robbins has been studying the behavioral ecology, reproductive strategies, and social system of mountain gorillas for 13 years, in Bwindi Impenetrable National Park, Uganda, as well as the Virungas. Alastair McNeilage studied gorilla ecology in the Virungas and Central African Republic, and now leads a local research institute developing applied conservation programmes in Uganda. 